$\xi=$

\title{
Antimicrobial and antidiabetic potentials of processed finger millet (Eleusine coracana)
}

\author{
Japhet Erasmus Aisoni ${ }^{1}$, Muhammad Yusha'u ${ }^{2}$, Olukayode Olugbenga Orole ${ }^{3}$ \\ ${ }^{1}$ Elbe Pharma Nigeria Limited, Ajao Estate, Lagos, Nigeria \\ ${ }^{2}$ Department of Microbiology, Faculty of Life Science, Bayero University Kano, Nigeria \\ ${ }^{3}$ Department of Microbiology, Federal University Lafia, Nassarawa State, Nigeria. \\ *Corresponding author E-mail: Orole Olukayode; e-mail: orolekayode@yahoo.com
}

\begin{abstract}
Finger millet is a food crop with energy value, phytochemical constituents, and minerals, hence its use as whole flour for traditional food preparation among traditional people. The study was designed to determine the glycaemic index and blood glucose level in albino rats, and the antimicrobial potential of processed finger millets. Finger millets were processed by fermentation and roasting, and methanolic extracts obtained used to test antimicrobial activity. Albino rats (18) divided into three groups were fed fermented, roasted, and unprocessed millet (control), and glycaemic index and blood glucose level determined. Another 25 rat were treated into 5 groups of diabetic rats without treatment, diabetic rats treated daily with Metformin, diabetic rats fed $20 \%$ millet, diabetic rats fed $40 \%$ millet, and untreated group (control). At $100 \%$ concentration, roasted and fermented millet obtained inhibition of $15 \mathrm{~mm}$ and $14 \mathrm{~mm}$ against Salmonella typhi, while the control drug $25 \mathrm{mg} / \mathrm{ml}$ streptomycin had $17 \mathrm{~mm}$ inhibition. While values obtained for the glycemic indexes were close though significantly different from each other (roasted - 36.83 \pm 1.23 ; fermented - 38.73 \pm 1.87 ), roasted millet brought about the highest reduction in blood glucose level 90.9 and $65.1 \mathrm{mg} / \mathrm{dl}$ at 60 and $120 \mathrm{~min}$ respectively compared with fermented millet with 125.1 and $100.2 \mathrm{mg} / \mathrm{dl}$ respectively at the same time. Animals administered finger millet in Groups 3 and 4-showed regeneration of the islet cells. The millet had the capacity to bring about healing of necrotic cells while also restoring and maintaining glucose levels in blood of subjects.
\end{abstract}

Keywords: Albino; Antimicrobial; Glycemic; Regeneration; Millet

\section{Introduction}

African finger millet also known as Eleucine coracana is a cereal grown in the arid areas of Africa and Asia. The Hausa call it tamba and the Yorubas call it oka. It is a reservoir of phytochemicals, minerals, anti-nutrients, and important proximate metabolites (Chethan and Melleshi, 2007). The millet could be consumed raw, cooked, or subjected to other processing method such as milling, boiling, and roasting as generally practiced in Nigeria. It can be sustained in good viable condition for many years without treatment, and infestation by insects and pests which makes it a reserve food. Phytochemicals in cereals has potential health benefits, and AparicioFernandez et al. (2005) and Reynoso-Camacho et al. (2006) explained that the seed coat habours rich fractions of such metabolites. Diabetes mellitus is characterized by hyperglycemia, resulting from insufficient or inefficient insulin secretion, with alterations in carbohydrate, protein and lipid metabolism. It results in deficient insulin production (Type 1) or combined resistance to insulin action and the insulin secretory response (Type 2). Diabetes is a scourge with increasing prevalence among the rich and the poor, urban dwellers are those living the rural areas in developing countries (Colagiuri, 2005). The problem of management of the disease is a frontal challenge for health workers and patients as it alters feeding regimens. A good nutritional plan serves as the cornerstone of any diabetes management, therefore, eating healthy and increased physical activity helps prevent and effectively manage diabetes and related diseases.
Consumption of whole grains, cereals and products provides the primary sources of nutrition and health benefits for diabetics and non-diabetics (Krings et al., 2000). The main difference in dietary requirements of a diabetic and non-diabetic is the regimentation of food intake that constitutes the corner stone of diabetic therapy such as timing of food intake, the caloric value of the food and the proportions and quantity of carbohydrates, fats and proteins which are important aspect of the dietary management for achieving the objectives of diet therapy, and by creating a situation in which the diabetic lives healthy and full lifestyle, with normal longevity (WHO, 2010). Cereals contains high level dietary fibre with health promoting phytochemicals (Bouchenak and Lamri-Senhadji, 2013; Pulse Canada, 2013).

Education, communication and knowledge of available locally grown, affordable diet can be used to build strong immunity, helps prevents diseases and specifically manage diabetes mellitus is important. The aim of this work was to determine the glycaemic index, blood glucose level in albino rats, and antimicrobial potential of differently processed finger millets.

\section{Materials and methods}

a) Procurement and processing of finger millet Commercially available finger millet were obtained and identified at the Herbarium unit of the Department of Biological Sciences, Ahmadu Bello University, and Zaria with a voucher No 24356. The millets were processed by a) roasting for $10-15 \mathrm{~min}$ in an open 
pan b) fermenting by soaking the seed in clean water and covering with a sack for $24 \mathrm{~h}$ and then sun-dried.

b) Preparation of extracts

The dried powdered sample were successively extracted from the fermented and roasted grains with methanol in Soxhlet apparatus and stored at $4^{\circ} \mathrm{C}$.

c) Test microorganisms

Bacillus subtilis, Salmonella typhi, Escherichia coli, Shigella sonnei, and Candida albicans were the test organisms for the study. The microbes were obtained from the Department of Medical Microbiology, Ahmadu Bello University Teaching Hospital, Zaria, Nigeria.

d) Antimicrobial assay

Antimicrobial susceptibility test was done using modified methods of Perez (1990). Agar well diffusion of the extract was used to determine the antibacterial and antifungal activities of the finger millet. Nutrient agar plates were inoculated with the different test microorganism by spreading the bacterial inoculums under aseptic conditions. Wells of $5 \mathrm{~mm}$ diameter were punched in the agar medium with sterile cork borer and filled with extracts. Streptomycin was the positive control for bacteria, while fluconazole was for the fungus after which the plates were incubated at $37^{\circ} \mathrm{C}$ for $24 \mathrm{~h}$. The negative control was unprocessed finger millet extract. The antimicrobial activity was assessed by measuring the diameter of the zone of inhibition for the respective plant extract and antibiotics.

e) Determination of Glycaemic Index

The prepared food products from processed and unprocessed were analysed for glycemic index

i) Animal subjects

Forty 3 (43) Albino rats weighing between 220 - 250 g were used in the study. They were kept in $12 \mathrm{~h}$ light and $12 \mathrm{~h}$ dark conditions and provided animal feed and water ad libitum at temperature $25 \pm$ $2^{\circ} \mathrm{C}$ until the end of the study. Maintenance of the animals followed "Guide for care and use of laboratory animals in research and teaching" by the National Academy of Science, published by the National Institute of Health (NIH) publication 86-23 (1985 revised). Eighteen (18) of the rats were used in the determination of the glycaemic index. They were divided into three groups of six rats each. One group given fermented finger millet, the second group was fed with roasted grain, while the third group was served with the whole unprocessed grain standard feed as control.

ii) Analysis of blood glucose in the rats

All subjects for investigation were made to fast overnight (10-12 h), and their blood was collected by tail prick using a hypodermic needle. Each blood sample was inserted into a calibrated glucometer (Accu-check/ one touch) which was read after 45 seconds incubation based on glucose oxidase assay method. The determination of blood sugar was taken at intervals i.e. 0 fasting, $15 \mathrm{~min}, 45 \mathrm{~min}, 60$ $\mathrm{min}, 90 \mathrm{~min}$, and $120 \mathrm{~min}$ after feeding the experimental diets. Postprandial blood sugar (PPBS) was taken at 15, 30, 45, 60, 90, and
120 minutes interval after consumption of test food or Control Food (food containing $50 \mathrm{~g}$ carbohydrate) as standard.

iii) Induction of diabetes

Diabetes mellitus was induced by administration of a single dose (i.p.) of $55 \mathrm{mg} / \mathrm{kg}$ of Streptozotocin, dissolved in $0.1 \mathrm{M}$ fresh cold citrate buffer ( $\mathrm{pH} \mathrm{4.5)}$ into $12 \mathrm{~h}$ fasted rats (Burcelin et al., 1995). After 3 days of STZ post-injection, the blood sugar levels were determined with a glucometer (Acc-cheek Advantage Roche diagnostics $\mathrm{GmbH}$, Germany). Rats with fasting blood glucose levels $>126$ $\mathrm{mg} / \mathrm{dl}(11.1 \mathrm{mmol} / \mathrm{L})$ were considered diabetic hence, selected for experimentation.

The remaining 25 animals were divided into 5 groups made of 5 rats each. Group 1: Diabetic rats without treatment (Diabetic control, DC). Group 2: Diabetic rats treated daily with Metformin (2.5 $\mathrm{mg} / \mathrm{kg}$ body weight) daily (DE+STD DRG) Group 3: Diabetic rats fed with $20 \%$ finger millet (DE+20\%). Group 4: Diabetic rats fed with $40 \%$ finger millet (DE+40\%).Group 5: Non-diabetic and untreated (Normal control, NC).

f) Statistical Analysis

Data was analysed by (Analysis of Variance) ANOVA using SPSS 20.0 software. All analysis was carried in [3] replicates. The results were presented as means \pm SD of 3 determinations. The means separated using Tukey's test. Level of significance was set at $\mathrm{P} \leq 0.05$.

\section{Results}

a) Processed millet extract inhibition

After $24 \mathrm{~h}$ incubation as shown in Table 1, extracts of roasted finger millet gave better activities against Candida albicans, Salmonella typhi, Escherichia coli, and Bacillus subtilis when compared with fermented millet extract. Best inhibition of the microbes was recorded at $100 \%$ concentration of the two extracts; and the extracts at the four concentration tested showed the least potency against Candida albicans. At $100 \%$ concentration, roasted millet inhibited Escherichia coli $(16.0 \mathrm{~mm})$ and Salmonella typhi $(18.0 \mathrm{~mm})$ more than the positive control at $15.0 \mathrm{~mm}$ and $17.0 \mathrm{~mm}$ respectively.

Result in Table 2 saw retarding values by the extract of the processed finger millet. While the positive control maintained their inhibition of the microbes after $48 \mathrm{~h}$, the activities of the extracts of the processed millet had declined. Sharp decline was particularly noted at $100 \%$ concentration in Salmonella typhi and Escherichia coli that had reduced to $15.0 \mathrm{~mm}$ and 13.5 respectively for roasted millet, while fermented millet extract had $14.0 \mathrm{~mm}$ and $13.0 \mathrm{~mm}$ at $100 \%$ concentration for the two microorganisms respectively Positive Control - Streptomycin $25 \mathrm{mg} / \mathrm{ml}$ (bacteria) and fluconazole $25 \mathrm{mg} / \mathrm{ml}$ (fungi); Negative control - extract of unprocessed finger millet

Table 1: Inhibition of Microbes by Methanol Extracts of Fermented and Roasted Finger Millet after 24 Hours (Mm)

\begin{tabular}{|c|c|c|c|c|c|c|c|c|c|c|}
\hline \multirow{2}{*}{ Microbes } & \multirow{2}{*}{ Positive Control } & \multirow{2}{*}{ Negative Control } & \multicolumn{4}{|c|}{ Fermented Finger millet } & \multicolumn{4}{|c|}{ Roasted finger millet } \\
\hline & & & $25 \%$ & $50 \%$ & $75 \%$ & $100 \%$ & $25 \%$ & $50 \%$ & $75 \%$ & $100 \%$ \\
\hline Shigella sonnei & 15.0 & 4.0 & 5.5 & 7.5 & 9.0 & 14.0 & 5.0 & 7.5 & 10.0 & 14.0 \\
\hline Candida albicans & 13.0 & 3.0 & 4.0 & 5.0 & 6.5 & 11.0 & 4.5 & 6.0 & 8.5 & 12.0 \\
\hline Salmonella typhi & 17.0 & 5.0 & 7.0 & 9.5 & 10.5 & 17.0 & 7.5 & 10.0 & 12.0 & 18.0 \\
\hline Escherichia Coli. & 15.0 & 4.0 & 6.0 & 6.5 & 10.5 & 15.0 & 6.0 & 9.0 & 11.5 & 16.0 \\
\hline Bacillus subtilis & 14.0 & 4.0 & 5.0 & 6.0 & 9.0 & 12.5 & 5.5 & 6.5 & 10.0 & 13.0 \\
\hline
\end{tabular}

Table 2: Inhibition of Microbes by Methanol Extracts of Fermented and Roasted Finger Millet after 48 Hours (Mm)

\begin{tabular}{|c|c|c|c|c|c|c|c|c|c|c|}
\hline \multirow[t]{2}{*}{ Microorganisms } & \multirow[t]{2}{*}{ Positive Control } & \multirow[t]{2}{*}{ Negative Control } & \multicolumn{4}{|c|}{ Fermented Finger millet } & \multicolumn{4}{|c|}{ Roasted finger millet } \\
\hline & & & $25 \%$ & $50 \%$ & $75 \%$ & $100 \%$ & $25 \%$ & $50 \%$ & $75 \%$ & $100 \%$ \\
\hline Shigella sonnei. & 15.0 & 4.0 & 4.5 & 5.5 & 8.0 & 12.0 & 5.0 & 6.5 & 9.0 & 12.5 \\
\hline Candida albicans & 13.0 & 3.0 & 3.0 & 3.5 & 6.5 & 9.5 & 3.5 & 4.5 & 7.5 & 10.0 \\
\hline Salmonella typhi & 17.0 & 5.0 & 7.0 & 7.5 & 11.0 & 14.0 & 7.5 & 8.5 & 11.0 & 15.0 \\
\hline Escherichia coli & 15.0 & 4.0 & 5.0 & 6.0 & 10.0 & 13.0 & 5.0 & 7.0 & 10.5 & 13.5 \\
\hline Bacillus subtilis & 14.0 & 4.0 & 4.0 & 4.5 & 8.0 & 11.0 & 4.5 & 5.5 & 9.0 & 12.0 \\
\hline
\end{tabular}

Positive Control - Streptomycin (bacteria) and fluconazole (fungi); Negative control - extract of unprocessed finger millet

b) Glycaemic index and blood sugar concentration
The Control group fed $50 \mathrm{~g}$ carbohydrate had the highest glycaemic index of $44.07 \pm 1.67$, while roasted millet had $36.83 \pm 1.23$ as the lowest (Table 3). Glycaemic index values obtained for the different processing methods were significant at $\mathrm{P}<0.05$. Fermented finger 
millet brought about the highest blood glucose concentrations 125.1 $\mathrm{mg} / \mathrm{dl}$ at $60 \mathrm{~min}$. While an increasing trend was observed in all the treatments as time increases, after $60 \mathrm{~min}$, they all started to descend.

Table 3: Concentration of Blood Glucose (Mg/Dl) and Glycaemic Index of Processed Millet

\begin{tabular}{|c|c|c|c|c|c|c|c|}
\hline $\begin{array}{l}\text { Food } \\
\text { items }\end{array}$ & $\begin{array}{l}15 \\
\min \end{array}$ & $\begin{array}{l}30 \\
\text { min }\end{array}$ & $\begin{array}{l}45 \\
\min \end{array}$ & $\begin{array}{l}60 \\
\min \end{array}$ & $\begin{array}{l}90 \\
\min \end{array}$ & $\begin{array}{l}120 \\
\mathrm{~min}\end{array}$ & $\begin{array}{l}\text { Glycemic } \\
\text { index }\end{array}$ \\
\hline $\begin{array}{l}\text { Roaste } \\
\text { d grain }\end{array}$ & $\begin{array}{l}\mathrm{mg} / \mathrm{dl} \\
65 . \\
2\end{array}$ & $\begin{array}{l}75 . \\
3\end{array}$ & $\begin{array}{l}80 . \\
0\end{array}$ & 90.9 & 70.2 & 65.1 & $\begin{array}{l}36.83^{\mathrm{a}} \pm 1.2 \\
3\end{array}$ \\
\hline $\begin{array}{l}\text { Fer- } \\
\text { mented } \\
\text { grain }\end{array}$ & $\begin{array}{l}80 . \\
1\end{array}$ & $\begin{array}{l}84 . \\
2\end{array}$ & $\begin{array}{l}87 . \\
4\end{array}$ & $\begin{array}{l}125 . \\
1\end{array}$ & $\begin{array}{l}110 . \\
5\end{array}$ & $\begin{array}{l}100 . \\
2\end{array}$ & $\begin{array}{l}38.73^{\mathrm{b}} \pm 1.8 \\
7\end{array}$ \\
\hline C & $\begin{array}{l}74 . \\
5 \\
\end{array}$ & $\begin{array}{l}80 . \\
6 \\
\end{array}$ & $\begin{array}{l}86 . \\
7 \\
\end{array}$ & 92.4 & 74.3 & 68.6 & $\begin{array}{l}44.07^{\mathrm{c}} \pm 1.6 \\
7\end{array}$ \\
\hline
\end{tabular}

Means followed by different letters $(\mathrm{a}, \mathrm{b}, \mathrm{c})$ in the same column differ significantly $(\mathrm{P}<0.05)$; $\mathrm{C}-$ Control.

c) Blood glucose concentration in finger millet treated albino rats

As shown in Figure 1, decreasing values were recorded as treatment proceeded for animals in Group 2, 3, and 4 respectively. Diabetic rats not administered any treatment presented no reduction as the study proceeded. Diabetic animals treated with $40 \%$ SCM showed highest reduction in glucose level, while Non-diabetic and untreated animals did not record any significant increase in glucose level throughout the duration of the study.

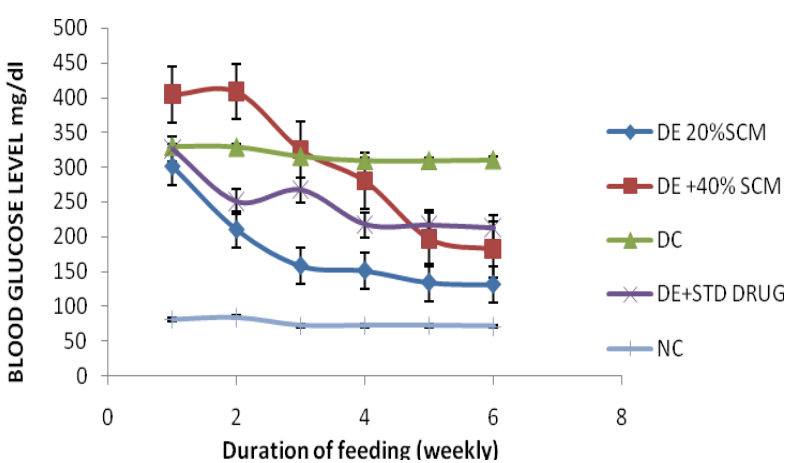

Fig. 1: Effect of Dietary Finger Millet SCM on Blood Glucose Levels of STZ Induced Diabetic Rats.

\section{Histopathological study of the pancreas}

Figure 1 showed the histo-pathological studies of the pancreatic tissues of the albino rats. Plates 2 and 3 showed slight regeneration of islet cells as compared to Plate 4 in which the DC showed necrosis of islet cells. Among the treated diabetic Groups, the DE+STD DRG group as seen in Plate 5 showed the most regeneration of islet cells.

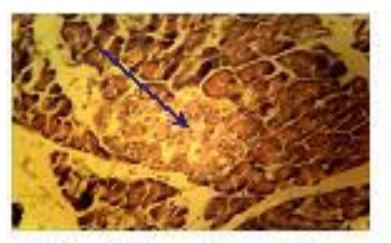

Plat 1: Norma control; Showing normal islet o:lls

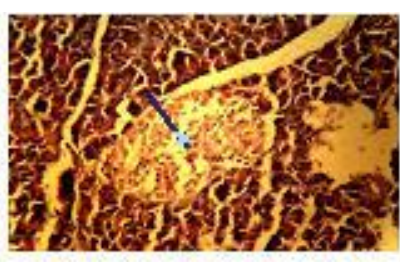

Plate 2:DE 20\%: Shoxing slight regeneration of is at cells

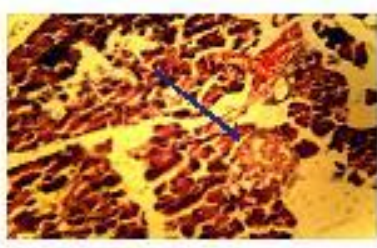

Plate 4: Diabetic control: Showingnecrosis of islet cells

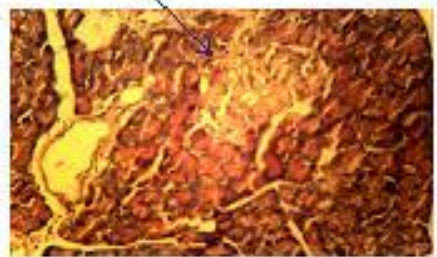

Flate 3:DE 40\%: Showing si git regeneration of is et olls

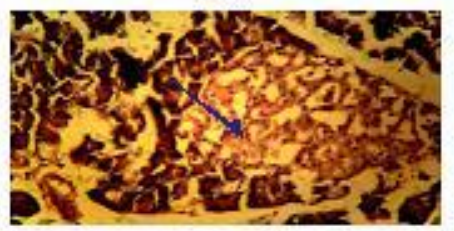

$$
\begin{aligned}
& \text { P1 de 5: DE +STD DRG :Showing } \\
& \text { regeneration of i idet cells }
\end{aligned}
$$

Fig. 2: Photomicrographs of Sections of Rat's Pancreas (H \& E Stain X 250), Showing $1=$ NC, 2 and $3=$ DE Group Treated with 20\% and 40\% Finger Millet SCM Respectively, 4 = DC and [5] = DE Group Treated with A Standard Drug (Metformin).

\section{Discussion}

The inhibition recorded by the methanolic extract of finger millet not minding the processing method could be ascribed to the presence of antimicrobial metabolites and phytochemicals present in the extracts. Phytochemicals occur naturally in plants depending on growing conditions, age at harvest, extraction methods, and have protective or disease preventing potentials (Anjorin et al., 2013). Phenol, flavonoids, tannins saponin, alkaloids, and anthocyanins are ample in finger millet (Chethan and Melleshi, 2007). Terpenoids from research confers antioxidant, antimicrobial, antifungal, antiviral properties on plants, while phenols are antimicrobial especially against Gram-positive bacteria (Tiwari et al., 2009; Ayoola and Adeyeye 2010).

The result presented in this study agreed with Viswanath et al. (2009) and Xu et al. (2011) who showed antimicrobial activities of extracts and fractions of millet grain against Bacillus cereus and $A s$ pergillus flavus and other microorganisms. Banerjee et al. (2012) showed that phenolic and flavonoids of finger millet could inhibit the of proliferation of E. coli, B. cereus, Listeria monocytogenes, Staphylococcus aureus, Streptococcus pyogenes, Serratia marcescens, Proteus mirabilis, Pseudomonas aeruginosa, Klebsiella pneumonia and Yersinia enterocolitica. Roasting from the unpublished report of Aisoni et al. (2018) reduces and removes flavonoid, steroids, and saponin from finger millet and still yielded better inhibitory activity than fermented finger millet. This might be because of roasting reducing the water content of the grains thus making the available phytochemicals more concentrated and more potent.

The glycaemic index is a figure representing the relative ability of a carbohydrates food to increase the level of glucose in the blood. One food gives one glycaemic index value which could vary due to variety, response, cooking methods, processing and the length of 
storage. Differences are reported in glycaemic response from person to person, from day to day depending on blood glucose levels, insulin resistance, and other factors. Carbohydrates with low glycaemic index are slowly digested, absorbed, and metabolised and bring about lower and slower rise in blood sugar. Processing finger millet by fermentation and roasting drastically reduce the glycaemic index of the food when compared with the unprocessed millet. Both processing methods are encouraged as they will ultimately reduce insulin levels in the body.

Our finding corroborated report by Young (2009) who recommended finger millet preparations for diabetics because of its sustaining power and lower glycaemic responses in subjects. Lower glycaemic responses noted in the processed millet might be as a result of the presence of anti-nutritional factors in food products; which are capable of reducing starch digestibility and absorption (Lakshmi et al., 2002). Reports have shown that phytic acid, tannin, oxalic acids, hydrocyanic acid and saponins which are anti-nutrients have negative effect on animal and human health at high concentrations, these anti-nutrients can be greatly reduce by heating at $100^{\circ} \mathrm{C}$ (Njoku et al., 2014; Ladeji et al., 1995; Akwaowo et al., 2000; Ajibade et al., 2006). These anti-nutrients have widely distribution in leafy vegetables and cereal crops, and modify effects of other nutrients by reducing bio-availability of the nutrients (Okoro, 1989; Hurrel et al., 1992).

Fermented grain brought about high rise in the blood glucose concentration when compared with roasted grains and food treatment incorporated with $50 \mathrm{~g}$ carbohydrate. High glucose level obtained might be as a result of the treatment with fermented millet showed it has little anti-hyperglycaemic activities, while roasted millet brought about glucose concentration which gradually increased to $90.9 \mathrm{mg} / \mathrm{dl}$ at $60 \mathrm{~min}$, then decreased to $65.1 \mathrm{mg} / \mathrm{dl}$ at $120 \mathrm{~min}$. Findings in this study showed that roasted millet possess higher anti-hyperglycaemic activity. As reported by Scalbert et al. (2005), polyphenols among which is flavonoids are known to inhibit glucose absorption and it is absent in roasted millet (Aisoni et al., 2018 unpublished). When compared with other cereals, millet had been reported to bring about the lowest blood glucose, serum cholesterol, and triglycerides compared with other minor millets, while the processing bring about changes in the starch molecule depending on its type and processing employed (Malleshi, 2006; Kumari and Thayumanavan, 1997)

Increased observed in the blood sugar level was the result of diabetes induction using $55 \mathrm{mg} / \mathrm{kg}$ of Streptozotocin. Streptozotocin bring about liver injury which is the combination of series of metabolic process dysfunction to include DNA damage, disrupted protein synthesis, aberrant inflammatory response, lipid peroxidation, and mitochondrial respiration interference (Sorrenti et al., 2013). Subsequent feeding of rats saw healing as reductions in blood sugar level was recorded which agreed with findings by Rajasekaran et al. (2004). Injury that led to diabetes mellitus was caused by free radicals produced in the body in the course of normal metabolic processes such as oxidation of food substances, environmental agents, drugs and so on (Sen et al., 2010). Antioxidants, which could neutralize free radicals, have been reportedly found in cells and in plants (Jacob, 1995; and Sen et al., 2010). These substances have the capacity to mop up free radicals and prevent them from causing cell damage (Sen et al., 2010), and thus bring about protective effects by mopping free radicals.

Diabetes mellitus is characterized by hyperglycaemia, which alters carbohydrate, protein and lipid metabolism, and induce non-enzymatic glycosylation of various proteins, resulting in the development of chronic complications in diabetes (Chonge et al., 2004). Millet preparations with its high sustaining power is recommended for subject diabetes as it is slowly digested and absorbed, thus helping to control postprandial blood glucose sugar (Chonge et al., 2004). Gopalan et al. (2002) added that regular consumption of finger millet reduces the risk of diabetes mellitus and gastrointestinal tract disorders. Treatment of diabetes induced animals with $40 \%$ and $20 \%$ finger millet saw drastic reductions in blood glucose levels and subsequent amelioration of the pancreatic islet cells which might be the healing effects of phenolic antioxidants, glutathione, vitamin $\mathrm{E}$ and $\mathrm{C}$, and superoxide dismutase, catalase (Chonge et al., 2004; Hedge et al., 2005).

\section{Conclusion}

The study concluded that roasted finger millet had higher potential at inhibiting microorganisms, though both roasting and fermentation methods reduces glycaemic index in millets and therefore bring about reduction in blood glucose levels. Findings also showed the capabilities of finger millet to ameliorate and bring about healing in the liver and pancreas induced by streptozotocin through the antioxidants present in the grain.

\section{References}

[1] Ajibade SR, Balogun MO, Afolabi OO \& Kupolati MD (2006) Sex differences in the biochemical contents of Telfairia occidentalis Hook f. Journal of Food, Agriculture and Environment 4, 155-156.

[2] Akwaowo EU, Ndon BA \& Etuk EU (2000) Minerals and antinutrients in fluted pumpkin (Telfairia occidentalis Hook f.). Food Chemistry 70(2), 235-240. https://doi.org/10.1016/S0308-8146(99)00207$\underline{1}$.

[3] Anjorin ST. Jolaoso MA \& Golu MT (2013) Survey of incidence and severity of pests and diseases of okra (Abelmoschus esculentus L. Moench) and eggplant (Solanum melongena L.) in Abuja, Nigeria American Journal of Research Communication 1(11), 333-349.

[4] Aparicio-fernandez X, Yousef GG, Loarca-Pina G, DeMejia E \& Lila MA (2005) Characterization of polyphenolics in the seed coat of black Jamapa bean (Phaseolus vulgaris L.). J. Agric. Food Chem 53, 4615-4622. https://doi.org/10.1021/jf047802o.

[5] Ayoola PB \& Adeyeye a (2010) Phytochemical and nutrient evaluation of Carica papaya (pawpaw) leaves. IJRRAS 5 (3), 325-328.

[6] Banerjee S, Sanjay K, Chethan S \& Malleshi N (2012) Finger millet (Eleusine coracana) polyphenols:Investigation of their antioxidant capacity and antimicrobial activity. African Journal of Food Science 6(13), 362-374. https://doi.org/10.5897/AJFS12.031.

[7] Bouchenak M \& Lamri-Senhadji M (2013. Nutritional Quality of Legumes and their Role in Cardio metabolic Risk Prevention: A Re$\begin{array}{lllll}\text { view. J. } & \text { Med. } & \text { Food 165-198 }\end{array}$ https://doi.org/10.1089/jmf.2011.0238.

[8] Chethan S \& Malleshi NG (2007) Finger millet polyphenols: optimization of extraction and the effect of $\mathrm{pH}$ on their stability. Food Chem. 105, 862-870. https://doi.org/10.1016/j.foodchem.2007.02.012.

[9] Chonge NS, Nithya M, Rose C \& Chandra TS (2004) the effect of finger millet feeding on the early responses during the process of wound healing in diabetic rats. Biochim Biophys Acta 1689, 190201. https://doi.org/10.1016/j.bbadis.2004.03.004

[10] Colagiuri S (2005) Are lower fasting plasma glucose levels at diagnosis of type 2 diabetes associated with improved outcomes. UKPDS 61. Diabetes Care 25, 1410-1417. https://doi.org/10.2337/diacare.25.8.1410.

[11] Gopalan C, Ramshashtri BV \& Balasubramanian SC (2002) revised and updated by Narasinga Rao BS, Deosthale YG, Pant KC, Nutritive value of Indian foods.

[12] Hegde PS, Rajasekaran NS \& Chandra TS (2005) Effects of the antioxidant properties of millet species on oxidative stress and glycemic status in alloxan-induced rats. Nutr Res. 25, 1109-1120. https://doi.org/10.1016/i.nutres.2005.09.020.

[13] Hurrell R, Jillerat M \& Reddy M B (1992) Soy protein, phytate, and iron absorption in humans. American Journal of Clinical Nutrition 56, 573-578. https://doi.org/10.1093/ajen/56.3.573.

[14] Krings U, El-Saharty YS, El-Seany BA, Pabel B \& Berger K (2000). Antioxidant activity of extracts from roasted wheat germs. Food Chemistry 71, 91-95. https://doi.org/10.1016/S03088146(00)00148-5.

[15] Kumari SK \& Thayumanavan B (1997) Comparative study of resistant starch from minor millets on intestinal responses, blood glucose, serum cholesterol and triglycerides in rats. J Sci Food Agric. 75, 296-302. https://doi.org/10.1002/(SICI)10970010(199711)75:3<296::AID-JSFA877>3.0.CO;2-X.

[16] Ladeji O, Okoye ZSC \& Ojobe T (1995) Chemical evaluation of the nutritive value of leaves of fluted pumpkin (Telfairia occidentalis) Food Chemistry 25, 259-268.

[17] Lakshmi Kkumari P \& Sumathi S (2002) Effect of consumption of finger millet on hyperglycemia in non-insulin dependent diabetes 
mellitus (NIDDM) subjects. Plants Food Hum. Nutr. 57, 205-213. https://doi.org/10.1023/A:1021805028738.

[18] Malleshi NG (2006) Decorticated finger millet (Eleusine coracana) and process for preparation of decorticated finger millet.

[19] Njoku DN, Gracen VE, Offei SK, Asante IK, Danquah EY, Egesi $\mathrm{CN}$ et al. (2014) Molecular marker analysis of F1 progenies and their parents for carotenoids inheritance in African cassava (Manihot esculenta Crantz). African Journal of Biotechnology 13(40), 39994007. https://doi.org/10.5897/AJB2013.12244.

[20] Okoro EU (1989) The Chemical and biological evaluation of the nutrition value of a multimix weaning food formulated using local foodstuffs. M.Sc. Thesis, University of Calabar, Nigeria.

[21] Perez C, Paul M \& Bazerque P (1990) an antibiotic assay by agar well diffusion method. Journal of Acta Biology 15, 113-115.

[22] Pulse Canada (2013) Pulses and cardiovascular disease. Accessed online at: <www.pulsecanada.com> on April 5th, 2013.

[23] Rajasekaran NS, Nithya M, Rose C \& Chandra TS (2004) the effect of finger millet feeding on the early responses during the process of wound healing in diabetic rats. Biochim Biophys Acta 1689, 190201. https://doi.org/10.1016/j.bbadis.2004.03.004.

[24] Reynoso-Camacho R, Ramos-Gomez M \& Loarca-Pina G (2006) Bioactive Components in common beans (Phaseolus vulgaris L.). Adv. Agric. Food Biotechnol., 217-236.

[25] Scalbert A, Manach C \& Morand C (2005) Dietary polyphenols and the prevention of diseases. Crit. Rev. Food Sci. Nutr., 45, 287-306. https://doi.org/10.1080/1040869059096.

[26] Sen S, Chakraborty R, Sridhar C, Reddy YSR \& Biplab D (2010) Free radicals, antioxidants, diseases and phytomedicines: Current status and future prospect. International Journal of Pharmaceutical Sciences Review and Research 3(1), Article 021, 91-100.

[27] Sorrenti V, Di Giacomo C, Acquaviva R, Barbagallo I, Bognanno M \& Galvano F (2013) Toxicity of ochratoxin A and its modulation by antioxidants: A review. Toxins 5, 1742-1766. https://doi.org/10.3390/toxins5101742.

[28] Tiwari BK, Valdramidis VP, O'Donnell CP, Muthukumarappan K, Bourke P \& Cullen PJ (2009) Application of natural antimicrobials for food preservation. J. Agric. Food Chem 57, 5987-6000 https://doi.org/10.1021/jf900668n

[29] Viswanath V, Urooj A, \& Malleshi NG (2009) Evaluation of antioxidant and antimicrobial properties of finger millet polyphenols (Eleusine coracana) Food Chem. 114, 340-346. https://doi.org/10.1016/j.foodchem.2008.09.053.

[30] Xu W, Wei L, Qu W, Liang Z, Wang J, Peng X, Zhang Y \& Huang K (2011) A novel antifungal peptide from foxtail millet Seeds. J Sci Food Agric. 91, 1630-1637. https://doi.org/10.1002/jsfa.4359.

[31] Young PC (2009) a pilot study to determine the feasibility of low glycemic index diet as a treatment for overweight children in primary care practice. Ambul Pediatr 4(1), 28-33. https://doi.org/10.1367/1539-4409(2004)004<0028:APSTDT>2.0.CO;2. 